\title{
$\begin{array}{ll}\text { Research Square } & \begin{array}{l}\text { Preprints are preliminary reports that have not undergone peer review. } \\ \text { They should not be considered conclusive, used to inform clinical practice, } \\ \text { or referenced by the media as validated information. }\end{array}\end{array}$
}

\section{The PB1 Gene from H9N2 Avian Influenza Virus Showed High Compatibility and Increased Mutation Rate after Reassorting with a Human H1N1 Influenza Virus}

\author{
Hongrui Cui \\ Wageningen UR: Wageningen University \& Research https://orcid.org/0000-0002-8351-7579 \\ Guangsheng Che \\ Shanghai Veterinary Research Institute Chinese Academy of Agricultural Sciences \\ Mart CM de Jong \\ Wageningen UR: Wageningen University \& Research \\ Xuesong Li \\ Shanghai Veterinary Research Institute Chinese Academy of Agricultural Sciences \\ Qinfang Liu \\ Shanghai Veterinary Research Institute Chinese Academy of Agricultural Sciences \\ Jianmei Yang \\ Shanghai Veterinary Research Institute Chinese Academy of Agricultural Sciences \\ Qiaoyang Teng \\ Shanghai Veterinary Research Institute Chinese Academy of Agricultural Sciences \\ Zejun Li \\ Shanghai Veterinary Research Institute Chinese Academy of Agricultural Sciences \\ Nancy Beerens ( $\square$ nancy.beerens@wur.nl) \\ Wageningen University \& Research https://orcid.org/0000-0001-6756-4431
}

Research

Keywords: Reassortment, human influenza, avian influenza, H9N2, Mutation rate, NGS

Posted Date: October 5th, 2021

DOI: https://doi.org/10.21203/rs.3.rs-907889/v1

License: () (1) This work is licensed under a Creative Commons Attribution 4.0 International License. Read Full License

Version of Record: A version of this preprint was published at Virology Journal on January 25th, 2022. See the published version at https://doi.org/10.1186/s12985-022-01745-x. 


\section{Abstract}

Background

Reassortment between human and avian influenza viruses (AIV) may result in novel viruses with new characteristics that may threaten human health when causing the next flu pandemic. A particular risk may be posed by avian influenza viruses of subtype H9N2 that are currently massively circulating in domestic poultry in Asia and have been shown to infect humans. In this study, we investigate the characteristics and compatibility of a human H1N1 virus with avian H9N2 derived genes.

Methods

The polymerase activity of the viral ribonucleoprotein (RNP) complex from different reassortments was tested in luciferase reporter assays. Reassortant viruses were generated by reverse genetics in which genes of the human WSN-H1N1 virus (A/WSN/1933) were replaced by genes of the avian A2093-H9N2 virus (A/chicken/Jiangsu/A2093/2011). We replaced both the Hemagglutinin (HA) and Neuraminidase (NA) genes in combination with one of the genes involved in the RNP complex (either PB2, PB1, PA or NP). The growth kinetics and virulence of reassortant viruses were tested on cell lines and mice. The reassortant viruses were then passaged for five generations in MDCK cells and mice lungs. The HA gene of progeny viruses from different passaging paths was analyzed using Next Generation Sequencing (NGS).

Results

We discovered that the avian PB1 gene increased the polymerase activity of the RNP complex. Reassortant viruses were able to replicate in MDCK and DF1 cells and mice. Analysis of the NGS data showed a higher substitution rate for the PB1-reassortant virus. In particular, for the PB1-reassortant virus, increased virulence for mice was measured by increased body weight loss after infection in mice.

Conclusions

The higher polymerase activity and increased mutation frequency measured for the PB1-reassortant virus suggests that the avian PB1 gene may drive the evolution and adaptation of novel reassortant viruses to the human host. This study provides novel insights in the characteristics of novel viruses that may arise by reassortment of human and avian influenza viruses. Surveillance for infections with H9N2 viruses and the emergence of novel reassortant viruses in humans is important for pandemic preparedness.

\section{Background}

Highly pathogenicity avian influenza viruses (HPAIVs), specifically the H7 and H5 subtypes, are a continues threat to the poultry industry, as these viruses can cause up to $100 \%$ mortality in poultry. In contrast, low pathogenicity avian influenza viruses (LPAIVs) typically cause only mild or no clinical symptoms in poultry. Since the first identification of H9N2 isolated from quail in 1988 [1], H9N2 AIV have been isolated from poultry [2-5] and wild birds [6, 7] across Europe, Asia and North America. Since the 1990s, the wide-spread of H9N2 AIV in poultry had led to human infections in China [8, 9], Bangladesh [10], Pakistan [11] and Oman [12]. Three stable poultry lineages are recognized with the representative viruses, A/quail/Hong Kong/G1/1997 (G1), A/chicken/Beijing/1/94 (BJ94, also known variously as the Y280 or G9 lineage) and A/chicken/Hong Kong/Y439/1997 (Y439, also known as the Korean lineage) [13]. In 1998, the first human infection with H9N2 AIV was reported in Hong Kong [9], and in the same year, five human patients were confirmed infected with H9N2 AIV in Southern China [14]. Since that, a total of 70 laboratory-confirmed human cases were reported in southern China, other Asian countries and Africa based on the records of WHO till December 2020 [8, 15-17]. The clinical human cases with H9N2 AIV indicated that certain strain, e.g. G1 and BJ94 (Y280 or G9) have a preference for the human-like a-2,6-linked sialic acid (SA) receptor due to some specific gene mutations in the HA (Hemagglutinin) gene [18-20]. Further evolution of the H9N2 AIV may lead to adaptation of the virus to humans; however, no human-to-human transmission has been reported yet [21].

The co-circulation may enhance the evolution of H9N2 AIV with other LPAI or HPAl viruses in poultry due to reassortment events in which gene segments are exchanged between viruses. Evidence for this is provided by phylogenetic analysis of the (A/Quail/Hong Kong/G1/97) G1-like H9N2 AIV [22]. Reassortment events, in particular for the PB2 (Polymerase basic protein 2), HA, NP (Nucleoprotein), and NA (Neuraminidase) genes, resulted in rapid evolution of the H9N2 AIV, adapting the wild bird viruses to poultry. As H9N2 AIVs were shown to have the potential to infect humans, reassortment with seasonal human influenza viruses may also occur during co-infections. The exchange of gene segments between different viral strains can cause sudden changes in pathogenicity, virulence or transmission ability [23-25]. This can give rise to novel influenza viruses that are adapted to the human host. Experimental studies using a ferret model showed that reassortant viruses harboring H9N2 AIV surface genes and seasonal human H3N2 influenza virus internal genes are efficiently transmitted after adaptation by serial passaging [26]. In addition, human infections were reported with other zoonotic subtypes of avian influenza, such as H5Nx, H7N9, and H10N8 [27]. Genetic analysis of these zoonotic viruses revealed that they arose by re-assortment events with H9N2 AIVs, in which they obtained internal genes of H9N2 AIVs $[28,29]$. Several mutations were identified in internal genes of avian H9N2 strains that enhance transmission from poultry to mammals or increase virulence of the viruses [30, 31], such as the mutation 627E/701D in the PB2 gene.

Beside re-assortment events, the high mutation rate of influenza viruses also contributes to their fast evolution. Replication of the RNA genome is mediated by the virus encoded RNA polymerase, which is highly error prone. This results in virus population, or quasi-species, with high genetic diversity. This diversity allows a viral population to rapidly adapt to dynamic environments, thereby allowing instance escape from the host immune response or vaccination. In particular genetic changes in the two surface proteins, HA and NA, can lead to changes in the antigenicity of the virus [32]. The viral RNA polymerase complex is composed of the PB2, PB1 (Polymerase basic protein 1) and PA (Polymerase acidic protein) [33], packaged by the NP protein (a single-strand RNA-binding nucleoprotein) [34] to generate the viral ribonucleoprotein complexes (RNPs). The RNPs provide the minimal set of proteins required for transcription and 
replication of viral RNAs [35, 36]. The polymerase proteins were previously reported to affect replication and virulence of influenza viruses [37]. The PB2 protein was found to influence virulence [38,39] as well as host-preference [40,41]. A study on single gene reassortment identified a critical role for PB1 (in addition to HA and NA) gene in the high virulence of the 1918 pandemic influenza virus [42]. Reassortment events between human and avian influenza viruses in combination with rapid evolution and adaptation due to error-prone replication may lead to a novel human pandemic. In this study, we investigate the replication capacity of the human WSN-H1N1 virus in combination with avian polymerase genes derived from the A2093-H9N2 virus. We show that the PB1 gene of the H9N2 AIV is able to increase polymerase activity and error-rate of the reassortant human viruses. The avian PB1 gene thus may thereby drive the evolution of novel human reassortant viruses. As the H9N2 AIV is currently still circulating intensively in poultry populations in Asia, and human H9N2 infections have been observed, the emergence of novel reassortant viruses in humans must be carefully monitored for pandemic preparedness.

\section{Methods}

\section{Viruses and reverse genetic platform}

The reverse genetic systems for WSN (A/WSN/1933, H1N1, GenBank: LC333185.1) and A2093 (A/chicken/Jiangsu/A2093/2011, H9N2, GenBank: KP865958.1) [43] viruses have been constructed using the pBD bidirectional expression vector. The viruses were generated by reverse genetics as previously reported $[44,45]$. The reverse genetics system was used to generate stable-replicating reassortant viruses containing segments of A2093-H9N2 in the WSNH1N1 virus background. One of the internal genes of WSN/H1N1 (PB2, PB1, PA or NP) and the surface genes (both HA and NA) were replaced by that of the avian A2093-H9N2 virus to obtain PB2-reassortant, PB1-reassortant, PA-reassortant and NP-reassortant. The wild type (wt) A2093-H9N2 and WSN-H1N1 were also rescued in this system for control.

\section{Cell lines and Animals}

Madin-Darby Canine Kidney (MDCK) cells and avian DF-1 cells were cultured in Dulbecco's modified Eagle's medium (DMEM, high glucose Gibco ${ }^{\mathrm{TM}}$ ) containing $5 \%$ fetal bovine serum (FBS, Gibco ${ }^{\mathrm{TM}}$ ) and $1 \%$ penicillin-streptomycin. The 293 T cells were cultured with DMEM containing $10 \%$ FBS and $2 \mathrm{mM} \mathrm{L-glutamine}$ $\left(\mathrm{Gibco}^{\mathrm{TM}}\right)$. All cell lines were incubated at $37^{\circ} \mathrm{C}$ in humidified incubator with $5 \% \mathrm{CO}_{2}$.

Specific-pathogen-free (SPF) 4- to 6-week-old female BALB/c mice were purchased from Vital River Laboratories, Beijing, China. They were housed in isolators with air re-circulation system. The room housing isolators was controlled by the central air conditioning to $23-25^{\circ} \mathrm{C}$ with $40-60 \%$ humidity. Mice were housed under optimal light conditions and feed and water were provided ad libitum. Sawdust and corn cob beddings were provided in the isolators. Bedding materials, food and water were refreshed every week. Virus infection experiments were carried out in high containment facilities, each isolator had a separate aircirculation purification system. The mice were euthanized at the end of the experiment. Manure was removed at the end of the experiment.

\section{Activity of the reassortant polymerase in vitro}

A minigenome assay was performed to compare the activities of viral RNP complexes with one of the polymerase-related gene from avian influenza H9N2 (A2093) following the manufacturer's instructions of Dual-Luciferase Reporter 1000 Assay Systems (Promega Corporation, Wisconsin, USA). Briefly, we constructed 8 eukaryotic expression plasmids with genes from virus strains A2093-H9N2 and WSN-H1N1, in the backbone of the pCAGGS expression construct: A2093-PB2, A2093-PB1, A2093-PA, and A2093-NP and WSN-PB2, WSN-PB1, WSN-PA, and WSN-NP.

Then $1 \times 10^{5} 293$ T cells were cultured in 12-well plates together with the four protein expression plasmids (pCAGGS PB2, pCAGGS PB1, pCAGGS PA, and pCAGGS NP [0.5 g of each]) for each of the 8 RNP combinations of A2093-H9N2 and WSN-H1N1 virus proteins. The open reading frame (ORF) of Firefly Luciferase was inserted in the packaging signals of NA gene ( $N^{\prime} 183$ base pairs (bp) and C'157bp) of the PR8 strain (A/Puerto Rico/8/1934), was placed under control of the pPol I promoter, and was inserted into a multiple cloning site (MCS) of pUC18 plasmid (Takara Bio, Dalian, China). At 48 hours post transfection, the Relative light units (RLU) of Firefly Luciferase were measured on a GloMax 96 microplate luminometer (Promega) according to the manufacturer's instructions. As an internal control for the dual-luciferase assay, Renilla (20ng each, Promega) was used. The results were presented as the mean of three independent parallel experiments, with the standard deviation.

\section{Replication of H1N1/H9N2 reassortant viruses in MDCK cells and mice}

The growth kinetics of the rescued viruses were estimated by infection of mammalian MDCK cells, and avian DF-1 cells at 0.001 multiplicity of infection (MOI). The 70\%-80\% monolayer cells were prepared in three T25 flasks 12 hours before infection. One flask of cells was used for counting the number of cells. The other two are for parallel control. A total of $1 \mathrm{ml}$ virus solution was incubated on the cells for 1 hour at $37^{\circ} \mathrm{C}, 5 \% \mathrm{CO}_{2}$ incubator. After removing the virus

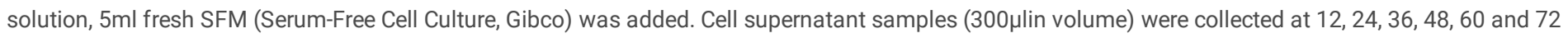
hours post infection to determine the virus titer.

The replication of the reassortant viruses in mice were estimated. For each infection group, three 4-week-old female BALB/c mice were infected intranasally with $10^{6} \mathrm{PFU}$ virus stocks in PBS (Phosphate-buffered saline). These mice were sacrificed for the tracheal and lung tissues at $4 \mathrm{~d}$.p.i. Clear supernatants of homogenates were used to evaluate the viral titer. Viral titers of these samples were determined in plaque-forming units per milliliter (PFU/ml) by plaque assays on MDCK cells as previously described [46]. Here we applied immunohistochemical staining method with influenza A virus nucleoprotein monoclonal antibody (clone FluA-NP 2C9) to count the plaques. Three independent experiments were carried out. Mean with standard error (sd) were used for data analysis.

Based on the replication ability and viral titer of parent virus strains, virulence of the virus were further evaluated by observing the body weight loss of infected mice. For each infection group, five 4-week-old female BALB/c mice were infected intranasally with $10^{6}$ PFU virus stocks in PBS (Phosphate-buffered saline). 
As control, five 4-week-old female BALB/c mice were inoculated with same amount of PBS. Five mice were numbered, the body weight and healthy condition were observed and record every 24 hours for 14 days post infection (d.p.i). The percentage of the body weight change after infection was calculated comparing to the original body weight measured before infection ( $0 \mathrm{~d}$.p.i). Average percentage body weight loss of five mice of every group were calculated. Multiple t-test with $\mathrm{a}=0.05$ were performed for significant differences.

\section{Serial passaging of H1N1/H9N2 reassortant viruses in cells and mice}

Reassortant viruses, wt WSN-H1N1 and A2093-H9N2 viruses were passaged in MDCK cells at a MOI of 0.001. In detail, three T25-flasks of $80 \%$ monolayer cells were seeded 12 hours before the infection. Parent virus was inoculated with cells at a $\mathrm{MOI}$ of 0.001 for one hour at $37^{\circ} \mathrm{C}, 5 \% \mathrm{CO}_{2}$. Cells were washed three times with SFM (Thermo Fisher Scientific) and then maintained with SFM for at least $24 \mathrm{~h}$ at $37{ }^{\circ} \mathrm{C}, 5 \% \mathrm{CO}_{2}$. The $\mathrm{HA}$ titer of supernatant and cell conditions were checked every 6 hours till the HA titer was over 16 HA Units and more than $70 \%$ cell lysis was observed. The progeny viruses were incubated for a new generation host-circle with the same amount of MDCK cells right after harvested from the previous generation.

In vivo, reassortant WSN-H1N1/A2093-H9N2 viruses and the corresponding wt WSN-H1N1 and A2093-H9N2) were passaged in 4-week-old BALB/c mice. Three mice were intranasally inoculated with $10^{6} \mathrm{PFU}$ parent virus stocks and sacrificed for the tracheal and lung tissues at 4 d.p.i. The homogenates of the two tissues from 3 mice were mixed separately, and subsequently used for infection (intranasally) of two groups of mice. One group as for serial passaging in mouse lung ( 3 mice), and the other group for the serial passaging in mouse trachea (3 mice). During the serial passaging, the age and health condition of the mice maintained the same as possible.

The above serial passaging procedures were repeated five times for five generations, and two independent parallel passaging experiments were performed.

\section{Sample preparation for NGS}

The reassortant WSN-H1N1/A2093-H9N2 viruses and the wt strains obtained after serially passaging in MDCK cells and mice (lung and turbinate, specifically) were prepared for Next Generation Sequencing (NGS). The initial virus stock and the last generation (P5) were selected for NGS sequencing. The details of sequenced viruses are listed in Supplementary Table S1 (Additional file2) and the experimental workflow of amplicon sequencing shown in Supplementary Fig S1 (Additional file1.pptx). All samples were analyzed in duplicate, starting from two independent RNA isolations.

Viral RNA (vRNA) was extracted from $140 \mu$ l supernatants from cell passaging or tissues' homogenates by using QIAGEN Viral RNA Isolation Kit following the manufacture's instructions. The isolated RNAs were all eluted into $30 \mu$ diethylpyrocarbonate-treated water. Two-step RT-PCR was employed to amplify each viral gene segment. The first-strand cDNA was transcripted by using Transcriptor High Fidelity cDNA Synthesis Kit (ROCHE, Cat. No. 05091284001$)$ with universal primer (5'-AGCAAAAGCAGG-3') for influenza A virus in a final volume of $20 \mu \mathrm{l}$ as manufacturer's protocol. The HA gene was amplified using primerpairs to obtain amplicons of approximately $500 \mathrm{bp}$ with PCR. Accordingly, there were 4 fragments of HA gene, 2 fragments of M and NS genes respectively. Six-nucleotide indexes were added to the forward primers for PCR to allow bar-coding of the samples (Supplementary Table S1). All the primers for PCR ware listed in Supplementary Table S2. In detail, the PCR amplification was carried out with Phanta Max Super-Fidelity DNA Polymerase (Vazyme Biotech Co.,Ltd) in a $50 \mu \mathrm{l}$ system, using $2 \mu \mathrm{l} \mathrm{cDNA}$ template. The amplification program consisted of a 3-min period at $95^{\circ} \mathrm{C}$ and was followed by 35 cycles with the following conditions: $95{ }^{\circ} \mathrm{C}$ for $30 \mathrm{sec}, 55^{\circ} \mathrm{C}$ for $30 \mathrm{sec}$, and $72{ }^{\circ} \mathrm{C}$ for $40 \mathrm{sec}$, and ended with one cycle at $72{ }^{\circ} \mathrm{C}$ for 5 min. The amplicons were purified in $1 \%$ agarose gel electrophoresis and then purified using a DNA Gel Extraction Kit (Axygen, Hangzhou, China). The concentration and quality were estimated by using NanoDrop 2000C. The concentration ranges of the PCR products were 15ng/ul-150ng/ul, and the 260/280 absorption was between 1.6-2.0. All bar-coded PCR products of the same gene fragment were mixed in equal quantities (30 ng) to construct one DNA library for NGS analysis. The DNA libraries were generated using VAHTS Universal DNA Library Prep Kit for Illumina.

\section{Analysis of NGS data}

The libraries were sequenced using Illumina MiSeq at 2×150 bp (4.5 Gb for 10-15M read pairs) configuration (Illumina, San Diego, CA, United States) at high coverage (average $>10000$ per nucleotide position) by GENEWIZ (Suzhou, China). Quality control-passed sequence reads were mapped using the WSN and A2093 virus reference sequences, and used to detect minority variants. The primer sequences were removed from the reads, then overlapping region of two PCR fragments was avoid by mapping the reads till the median location. From the mapped data, we obtained the reads counts (sequencing depth) of each nucleotide type (A/T/C/G) at every location of the whole length of HA gene, $N_{i j}$ ( $i$ is the position of the substitution on the gene; $j$ refers to one nucleotide type, $A / T / C / G)$. Then the frequency of each nucleotide type at the location can be approached as $f_{i j}=N_{i j} / C_{i}\left(C_{i}\right.$ is the sequencing depth at location $\left.i\right)$. Based on the reference sequence, total substitution frequency at every location was available as $\mathrm{f}_{\mathrm{i}}=\sum_{\mathrm{j}}^{3} f_{i j}$ (Supplementary Table S3). Under the assumption that the sequencing errors, that occurred at every location of the gene, are identically independent distributed with a binomial distribution, the probability of observing a substitution follows approximately a Poisson distribution because these probabilities are low. Binning the $\mathrm{f}_{\mathrm{i}}$ with a range of 0.001 , we identified the low frequency sequencing errors occur in bins before bin $0.005-0.006$ with the threshold $>0.05$ (threshold analysis was based on the parent A2093 data). Therefore, $\mathrm{f}_{\mathrm{i}} \geq 0.6 \%$ were filtered as minority single base substitutions (SBS). Geometric mean of minority SBS indicating the mutation rate of these "hotspots" on HA gene. This was calculated by the geometric mean $F g=\left(\prod_{i}^{n} f_{i}\right)^{1 / n}, n$ represented the nucleotide number of the locations with $f_{i} \geq 0.6 \%$. However, the general mutation rate over a certain domain of the $\mathrm{HA}$ gene $\left(\mathrm{F}_{\mathrm{g}}\right.$ per nt) was calculated by the arithmetic mean Fg per $\mathrm{nt}=1 / \mathrm{N} \sum_{\mathrm{i}}^{\mathrm{N}} f_{i}, N$ was the nucleotide numbers of the sequence region of HA gene. The genetic distance between two virus stock $A$ and $B$ was calculated with a population wide measure $\mathrm{d}=\sqrt{\frac{1}{N} \sum_{i}^{n}\left(f_{i A}-f_{i B}\right)^{2}}[47]$ viruses $\left(f_{i A}\right)$ to that of parent A2093-H9N2 $\left(f_{i B}\right)$. Calculations were programmed in R Studio [48]. 
For the calculation of transition/transversion and non-synonymous mutations, we extended the threshold of fi to $\geq 1 \%$, as detection limit for reliable recognition of variants in the viral [49] and the background error from PCR and sequencing. For transition/transversion definition, one SBS with $\mathrm{fi} \geq 0.01$ observed at one location was counted as one occurrence of transition (Ts) or transversion (Tv) basing on the consensus sequence. Sum of all the $f_{i}$ of transition or transversion over the whole genome was the probability that transition and transversion observed after selection, as $\mathrm{P}_{\mathrm{Ts}}$ and $\mathrm{P}_{\mathrm{TV}}$. Simultaneously, the total numbers of Ts and Tv were summed up, which indicating the diversity of one viral population (one virus stock).

Data in detail are displayed in Supplementary Table S4. Two parallel independent NGS runs (run1, run2) were performed to analyze the reproducibility of the results. NGS data from these two runs of sequencing were compared. Multiple t-test Discovery was applied using the Two-stage linear step-up procedure of Benjamini, Krieger and Yekutieli, with $Q=1 \%$. Each row was analyzed individually, without assuming a consistent SD by using GraphPad Prism.

\section{Results}

\section{Polymerase activity of reassortant viruses in vitro}

The polymerase activity of the avian A2093-H9N2 influenza virus was compared to that of the human WSN-H1N1 influenza virus using an in vitro Luciferase reporter assay. In addition, reassortant H1N1 and H9N2 polymerases were tested in which either the PB2, PB1, PA or NP genes were exchanged between the two viruses. The activity of the recombined polymerases was compared to that of the WSN-H1N1 and A2093-H9N2 polymerases (Fig. 1). Compared to the WSN-H1N1 polymerase, the reassortant polymerase containing the PB1 gene of the avian A2093-H9N2 virus significantly increased the activity of polymerase complex in vitro (mean diff. $-7.245,95 \% \mathrm{Cl}$ of diff. -12.76 to -1.734 ). Replacement of the PB2 or PA genes dramatically decreased the polymerase activity (mean diff. were 22.57 and 20.07 respectively), whereas replacement of NP did not significantly affect the activity (mean diff. $-0.09848,95 \%$ Cl of diff. -5.610 to 5.413$)$.

\section{Replication of the reassortant viruses in cells}

Reassortant WSN-H1N1 viruses were generated, in which both the HA and NA genes were replaced by that of A2093-H9N2, in combination with one of the polymerase-related genes PB2, PB1, PA or NP. The replication of these viruses was studied after infection of mammalian MDCK cell and duck DF1 cells, as shown in Fig. 2A. The viral titers of wild-type and reassortant viruses were evaluated using plaque assays and HA titers were determined (Table 1 ). In MDCK cells, the replication of the PB1-reassortant viruses was similar to that of wt WSN-H1N1 virus. The peak viral titers were obtained after 24 hrs, $2.83 \times 10^{6}$ ( \pm 1.17 $\left.\times 10^{6}\right) \mathrm{PFU} / \mathrm{ml}$ for wt WSN-H1N1, and $5.69 \times 10^{6}\left( \pm 1.10 \times 10^{6}\right) \mathrm{PFU} / \mathrm{ml}$ for the PB1-reassortant virus. For the other reassortant viruses, delayed replication kinetic peak and lower titers were observed: $2.21 \times 10^{4}\left( \pm 1.23 \times 10^{4}\right)$ PFU/ml for PB2-reassortant to $1.28 \times 10^{6}\left( \pm 1.25 \times 10^{6}\right)$ PFU/ml for PA-reassortant. On DF1 cells titers of around $10^{2}-10^{5} \mathrm{PFU} / \mathrm{ml}$ were obtained for the reassortant viruses, whereas a peak titer of $2.09( \pm 1.2) \times 10^{5} \mathrm{PFU} / \mathrm{ml}$ was observed for wt WSN-H1N1 virus at $24 \mathrm{hpi}$. On DF1 cells, lower peak viral titers were observed compared to MDCK cells. Due to inefficient replication on DF1 cells, MDCK cells were selected for subsequent serial passaging experiments with the reassortant viruses.

\section{Replication and virulence of reassortant viruses in mice}

Virus replication for the reassortant viruses was studied by infection of mice. At four days post infection, virus titers in the mouse lung and nasal turbinate were measured (Fig. 2B). The human-originated WSN-H1N1 virus replicated more efficiently in mice than the avian A2093 virus, likely due to its adaptation to replication in mammals. The replication of the reassortant viruses containing either the A2093-H9N2 PB2 or NP genes was reduced compared to wt WSNH1N1 virus. However, virus replication of the WSN-H1N1 was not significantly affected by replacement with the avian PB1 and PA genes. That is, these two reassortant viruses were able to replicate in both turbinate and lung up to $10^{4} \mathrm{PFU} / \mathrm{ml}$. The A2093-H9N2 showed a slight preference for replication in the lung compared to turbinate. The reassortant viruses were able to replicate to titers of $10^{3} \mathrm{PFU} / \mathrm{ml}$ (without significant differences between the viruses), except for PB2-reassortant virus for which significantly lower titers were obtained. These results show that lowest levels of replication were observed for the PB2reassortant virus in both cell lines and mice, whereas the other reassortant viruses replicate to similar levels.

To study the virulence of the reassortant viruses, we inoculated 8 mice with the reassortant viruses that were found to efficiently replicate in mice (PB1, PA and NP-reassortant viruses). Subsequently, the body-weight loss of five mice was measured during 14 days after infection as a marker for virulence. This showed that the PB1-reassortant virus caused significant body-weight drop (Fig. 3) in infected mice, similar to the wt WSN-H1H1 virus at the 5th, 6th and 7th d.p.i. After inoculation with the PB1-reassortant virus, significant body-weight loss was observed with decreasing trend on 5th, 6th and slight increasing trend on 7th and 8th d.p.i. The increasing trend of WSN-H1N1 strain was observed after 10 d.p.i. No weight loss was observed for the NP-reassortant and PA-reassortant viruses, however the PA-reassortant virus was detected at low level in lung and turbinate at 4 d.p.i (Fig. 2B). In conclusion, the PB1-reassortant virus was able to replicate in mice and resulted in significant body weight loss.

\section{Serial passaging of reassortant viruses}

To study the replication and evolution of the viruses during prolonged passaging, the reassortant viruses and wt A2093-H9N2 virus were passaged in both MDCK cells and in mice. As a result of low replication for the PB2-reassortant virus in both cell lines and mice, we were unable to obtain the progeny viruses of this reassortant strain. However, five generations of progeny viruses of the PB1, PA and NP-reassortant viruses and wt A2093-H9N2, WSN-H1N1 virus were collected from serial passaging on MDCK cells.

These reassortant viruses and the A2093-H9N2 virus were also successfully passaged for five generations in mice. Viruses harvested from individual mouse lung or turbinate were pooled and inoculated into the next group of mice. We were able to continue passaging for five generations in mice lung, however, for 
turbinate only one generation was successful.

The viral titers of parent virus before inoculation and the 5th generation of progeny viruses is listed in Table 1. For the following analysis, the PB2-reassortant strain was not included due to unsuccessful serial passaging. There was no significant difference in the titers obtained for the other viruses, suggesting a similar population size for subsequent analysis of viral sequences.

Table 1

The viral titers of viruses before and after 5-generation's serial passaging.

\begin{tabular}{|c|c|c|c|c|}
\hline Rescued viruses & $\begin{array}{l}\text { Parent Virus HA } \\
\text { titer (log2) }\end{array}$ & $\begin{array}{l}\text { Parent Virus (generation } 0) \\
\left(\log 10^{c o p i e s} / \mathrm{ml}\right)^{\mathrm{a}}\end{array}$ & $\begin{array}{l}\text { 5th Generation from MDCK cell line } \\
\text { (log10 copies/ml) }\end{array}$ & $\begin{array}{l}\text { 5th Generation from Mouse lung } \\
\text { (log10 copies/ml) }\end{array}$ \\
\hline A2093HANAPB2/WSN & 10 & $8.05 \pm 0.02$ & $2.16 \pm 0.17$ & $2.56 \pm 0.82$ \\
\hline A2093HANAPB1/WSN & 6 & $7.09 \pm 0.04$ & $7.59 \pm 0.01$ & $6.59 \pm 0.48$ \\
\hline A2093HANAPA/WSN & 10 & $8.33 \pm 0.06$ & $5.48 \pm 0.00$ & $7.31 \pm 0.28$ \\
\hline A2093HANANP/WSN & 9 & $8.06 \pm 0.20$ & $2.33 \pm 0.05$ & $6.73 \pm 0.27$ \\
\hline A2093 & 11 & $7.76 \pm 0.02$ & $6.60 \pm 0.00$ & $6.16 \pm 0.03$ \\
\hline WSN & 7 & $7.87 \pm 0.04$ & $6.74 \pm 0.00$ & $7.86 \pm 0.30$ \\
\hline
\end{tabular}

\section{General mutation frequency and hot-spots on HA gene}

We analyzed the mutation rate of the reassortant viruses during serial passaging in both MDCK cells and mouse lung. The virus population was analyzed by Illumina sequencing, the reads were mapped onto the HA ORF region of the reference sequence. Comparing the mutation rates $\left(F_{\mathrm{g} / \mathrm{nt}}\right.$, mutation/site/infection cycle) calculated from the HA1 and HA2 region (Table 2), after five passages in mouse lungs, showed that the net mutation rates (after selection) of the PB1and PA-reassortant viruses were almost 2-3 times higher than that of A2093-H9N2 and WSN-H1N1 strains. The genetic distance in the HA sequences of the viruses after 5 passages in MDCK cells and mouse lung was calculated (shown in Fig. 4A). This analysis showed that for the PB1- and PA-reassortant viruses, the genetic distance in the HA sequences significantly increased compared to that of the wt A2093-H9N2 virus after passaging in mouse lung. No significant difference was observed for the NP-reassortant after passaging in mouse lung. For none of the viruses a significant difference in the genetic distance was observed after passaging in MDCK cells. The genetic distances of the HA sequences observed during passaging of the PB1- and PA-reassortant viruses in mouse lung were also larger than measured during passaging of the WSN-H1N1 virus (Fig. 4A, details in Supplementary Table S5). Differences were observed in the substitution frequency measured for different domains in the HA gene (Table 2). The region from 350 to 950 on HA nucleotide sequence (marked as $\mathrm{HA} 1^{\mathrm{b}}$ in Table 2) includes the 130 helix, RBS and 220 loop domains of HA head. The mutation frequency in this functional HA1 domain was compared to that of the complete HA gene, and that of the HA2 domain (region 1015-1615 for A2093, region 1030-1630 for WSN). The general mutation rates ( $F_{g / n t}$ mutation/site/infection cycle) over the HA1 domain was 2.1 times (Std. Error $=9.425 \mathrm{E}-02$ ) higher than that over the whole HA domain (in linear regression with $\mathrm{F}_{\mathrm{g} / \mathrm{nt}}\left(\mathrm{HA}^{\mathrm{b}}{ }^{\mathrm{s}}\right)=2.13 \mathrm{~F}_{\mathrm{g} / \mathrm{nt}}$ (whole HA), $\mathrm{R}^{2}=0.967$, p-value = 3.938e-14). The plot of the dataset containing $\mathrm{F}_{\mathrm{g} / \mathrm{nt}}$ of different HA domains were visualized in $\mathrm{R}$, and exported on Supplementary Fig S2 (Additional file1). The general mutation rates over the HA2 domain displayed no linear relationship with that over the whole HA regions (Table 2), and the general mutation rates of the HA2 domain were lower than the HA1 domain for all the progeny viruses. These results suggest that the HA1 region, for with higher substitution frequency was measured, reflects a mutation "hot-spot" on the HA gene. This is likely due to increased selective pressure on this functional HA domain. 
Table 2

The geometric mean of substitution frequency and general mutation rate of viruses from 5 th generation.

\begin{tabular}{|c|c|c|c|c|c|c|c|}
\hline \multirow[t]{2}{*}{ Virus strain } & \multirow[t]{2}{*}{$\begin{array}{l}\text { Origination of the } 5 \text { th } \\
\text { generation }\end{array}$} & $F_{g}$ & $F_{g / n t}{ }^{d}$ & $F_{g}$ & $F_{g / n t}$ & $F_{g}$ & $F_{g / n t}$ \\
\hline & & \multicolumn{2}{|l|}{$\mathrm{HA}^{\mathrm{a}}$ (RUN1, RUN2) } & \multicolumn{2}{|c|}{ HA1 ${ }^{b}$ (RUN1, RUN2) } & \multicolumn{2}{|c|}{$\mathrm{HA}^{\mathrm{C}}{ }^{\mathrm{C}}$ (RUN1, RUN2) } \\
\hline A2093 & MDCK & $1.13 \mathrm{E}-02,0$ & $3.69 \mathrm{E}-05,0$ & $9.38 \mathrm{E}-03,0$ & $4.94 \mathrm{E}-05,0$ & $1.75 \mathrm{E}-02,0$ & $2.91 \mathrm{E}-05,0$ \\
\hline WSN & & $\begin{array}{l}\text { 1.84E-02, } \\
1.32 \mathrm{E}-02\end{array}$ & $\begin{array}{l}\text { 4.77E-05, } \\
1.37 \mathrm{E}-04\end{array}$ & $\begin{array}{l}2.10 \mathrm{E}-02 \\
1.63 \mathrm{E}-02\end{array}$ & $\begin{array}{l}3.49 \mathrm{E}-05 \\
5.82 \mathrm{E}-05\end{array}$ & $\begin{array}{l}\text { 1.67E-02, } \\
1.53 \mathrm{E}-02\end{array}$ & $\begin{array}{l}\text { 9.56E-05, } \\
2.47 \mathrm{E}-04\end{array}$ \\
\hline \multicolumn{2}{|l|}{ A2093HANAPB1/WSN } & $\begin{array}{l}\text { 2.35E-02, } \\
3.55 \mathrm{E}-02\end{array}$ & $\begin{array}{l}1.71 \mathrm{E}-04 \\
1.16 \mathrm{E}-04\end{array}$ & $\begin{array}{l}\text { 3.27E-02, } \\
3.55 \mathrm{E}-02\end{array}$ & $\begin{array}{l}\text { 4.16E-04, } \\
\text { 3.14E-04 }\end{array}$ & $1.58 \mathrm{E}-02,0$ & $2.63 \mathrm{E}-05,0$ \\
\hline \multicolumn{2}{|l|}{ A2093HANAPA/WSN } & $1.20 \mathrm{E}-02,0$ & $3.85 \mathrm{E}-05,0$ & 1.03E-02, 0 & $5.31 \mathrm{E}-05,0$ & $1.75 \mathrm{E}-02,0$ & $2.91 \mathrm{E}-05,0$ \\
\hline \multicolumn{2}{|l|}{ A2093HANANP/WSN } & 1.25E-02, na. & 4.82E-05, na. & 9.99E-03, na. & 5.21E-05, na. & $1.57 \mathrm{E}-02,0$ & $2.61 \mathrm{E}-05,0$ \\
\hline A2093 & MOUSE LUNG & $\begin{array}{l}\text { 1.43E-02, } \\
2.24 \mathrm{E}-02\end{array}$ & $\begin{array}{l}2.62 \mathrm{E}-04 \\
2.34 \mathrm{E}-04\end{array}$ & $\begin{array}{l}\text { 1.89E-02, } \\
3.72 \mathrm{E}-02\end{array}$ & $\begin{array}{l}\text { 6.00E-04, } \\
5.32 \mathrm{E}-04\end{array}$ & $\begin{array}{l}\text { 8.93E-03, } \\
1.22 \mathrm{E}-02\end{array}$ & $\begin{array}{l}\text { 9.18E-05, } \\
6.19 \mathrm{E}-05\end{array}$ \\
\hline \multicolumn{2}{|l|}{ WSN } & $\begin{array}{l}\text { 1.38E-02, } \\
1.63 \mathrm{E}-02\end{array}$ & $\begin{array}{l}2.90 \mathrm{E}-04 \\
2.62 \mathrm{E}-04\end{array}$ & $\begin{array}{l}\text { 1.64E-02, } \\
2.34 \mathrm{E}-02\end{array}$ & $\begin{array}{l}5.75 \mathrm{E}-04 \\
4.94 \mathrm{E}-04\end{array}$ & $\begin{array}{l}\text { 1.17E-02, } \\
1.31 \mathrm{E}-02\end{array}$ & $\begin{array}{l}\text { 1.45E-04, } \\
1.65 \mathrm{E}-04\end{array}$ \\
\hline \multicolumn{2}{|l|}{ A2093HANAPB1/WSN } & $\begin{array}{l}\text { 1.82E-02, } \\
2.49 \mathrm{E}-02\end{array}$ & $\begin{array}{l}5.03 \mathrm{E}-04 \\
4.98 \mathrm{E}-04\end{array}$ & $\begin{array}{l}\text { 1.77E-02, } \\
3.44 \mathrm{E}-02\end{array}$ & $\begin{array}{l}9.49 \mathrm{E}-04 \\
9.04 \mathrm{E}-04\end{array}$ & $\begin{array}{l}\text { 2.06E-02, } \\
2.12 \mathrm{E}-02\end{array}$ & $\begin{array}{l}\text { 3.91E-04, } \\
3.99 \mathrm{E}-04\end{array}$ \\
\hline \multicolumn{2}{|l|}{ A2093HANAPA/WSN } & $\begin{array}{l}\text { 3.96E-02, } \\
2.91 \mathrm{E}-02\end{array}$ & $\begin{array}{l}\text { 6.17E-04, } \\
6.13 \mathrm{E}-04\end{array}$ & $\begin{array}{l}\text { 4.91E-02, } \\
2.43 \mathrm{E}-02\end{array}$ & $\begin{array}{l}\text { 1.34E-03, } \\
1.38 \mathrm{E}-03\end{array}$ & $\begin{array}{l}\text { 4.66E-02, } \\
3.93 \mathrm{E}-02\end{array}$ & $\begin{array}{l}\text { 3.06E-04, } \\
2.80 \mathrm{E}-04\end{array}$ \\
\hline \multicolumn{2}{|l|}{ A2093HANANP/WSN } & $\begin{array}{l}\text { 1.30E-02, } \\
1.34 \mathrm{E}-02\end{array}$ & $\begin{array}{l}1.60 \mathrm{E}-04 \\
1.61 \mathrm{E}-04\end{array}$ & $\begin{array}{l}\text { 1.35E-02, } \\
1.35 \mathrm{E}-02\end{array}$ & $\begin{array}{l}\text { 3.36E-04, } \\
\text { 3.07E-04 }\end{array}$ & $\begin{array}{l}\text { 8.27E-03, } \\
9.55 \mathrm{E}-03\end{array}$ & $\begin{array}{l}\text { 4.15E-05, } \\
5.10 \mathrm{E}-05\end{array}$ \\
\hline \multicolumn{8}{|c|}{ 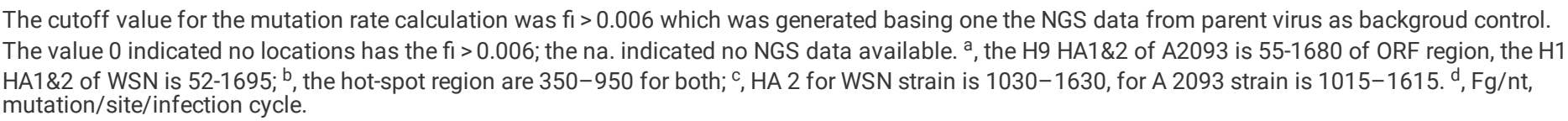 } \\
\hline
\end{tabular}

\section{Mutation preference of reassortant viruses}

We analyzed the substitutions observed in the HA ORF in further detail with a threshold of $f_{i} \geq 0.01$ for significant SBS after selection. The total number of SBS which reflects the diversity of the gene was calculated, as well as the number of transitions and transversion, and the number of synonymous and nonsynonymous mutations (Table 3). Few significant SBS were observed in the HA gene after serial passaging in MDCK cells. The total number of SBS detected in the HA ORF was highest for the PB1-reassortant virus after passaging in mice lung. Therefore, the gene diversity of the HA gene of PB1-reassortant virus was higher than estimates for the other reassortant viruses after five passages in mouse lungs. 
Table 3

Transition/transversion and non-synonymous mutations of viruses passaged for 5 generations.

\begin{tabular}{|c|c|c|c|c|c|c|c|c|c|c|c|c|c|c|c|}
\hline \multirow[t]{2}{*}{ Virus strain } & \multirow[t]{2}{*}{$\begin{array}{l}\text { Origination } \\
\text { of the 5th } \\
\text { generation }\end{array}$} & \multicolumn{2}{|c|}{ SBS Count } & \multicolumn{2}{|l|}{ Ts } & \multicolumn{2}{|l|}{ Tv } & \multicolumn{2}{|l|}{$\mathrm{P}_{\mathrm{Ts}}$} & \multicolumn{2}{|l|}{$\mathrm{P}_{\mathrm{Tv}}$} & \multicolumn{2}{|c|}{$\begin{array}{l}\text { Ratio of } \mathrm{P}_{\mathrm{Ts}} \\
\text { and } \mathrm{P}_{\mathrm{Tv}}\end{array}$} & \multicolumn{2}{|c|}{$\begin{array}{l}\text { Non- } \\
\text { synonymou: } \\
\text { count }\end{array}$} \\
\hline & & run1 & run2 & run1 & run2 & run1 & run2 & run1 & run2 & run1 & run2 & run1 & run2 & run1 & ruñ \\
\hline A2093 & MDCK & 0 & 0 & 0 & 0 & 0 & 0 & 0 & 0 & 0 & 0 & na. & na. & 0 & 0 \\
\hline WSN & MDCK & 3 & 9 & 3 & 9 & 0 & 0 & 0.0686 & 0.199 & 0 & 0 & na. & na. & 1 & 5 \\
\hline A2093HANAPB1/WSN & MDCK & 1 & 1 & 0 & 1 & 1 & 0 & 0 & 0.181 & 0.225 & 0 & 0 & na. & 1 & 0 \\
\hline A2093HANAPA/WSN & MDCK & 0 & 0 & 0 & 0 & 0 & 0 & 0 & 0 & 0 & 0 & na. & na. & 0 & 0 \\
\hline A2093HANANP/WSN & MDCK & 2 & na. & 1 & na. & 1 & na. & 0.0174 & na. & 0.492 & na. & 0.035 & na. & 1 & na. \\
\hline A2093 & $\begin{array}{l}\text { MOUSE } \\
\text { LUNG }\end{array}$ & 10 & 6 & 5 & 4 & 5 & 2 & 0.2446 & 0.228 & 0.109 & 0.074 & 2.249 & 3.092 & 10 & 6 \\
\hline WSN & $\begin{array}{l}\text { MOUSE } \\
\text { LUNG }\end{array}$ & 18 & 13 & 11 & 13 & 7 & 0 & 0.33 & 0.362 & 0.069 & 0 & 4.769 & na. & 14 & 9 \\
\hline A2093HANAPB1/WSN & $\begin{array}{l}\text { MOUSE } \\
\text { LUNG }\end{array}$ & 14 & 10 & 7 & 7 & 7 & 3 & 0.2554 & 0.249 & 0.811 & 0.771 & 0.315 & 0.323 & 11 & 8 \\
\hline A2093HANAPA/WSN & $\begin{array}{l}\text { MOUSE } \\
\text { LUNG }\end{array}$ & 4 & 3 & 3 & 3 & 1 & 0 & 0.9448 & 0.949 & 0.014 & 0 & 67.14 & na. & 4 & 3 \\
\hline A2093HANANP/WSN & $\begin{array}{l}\text { MOUSE } \\
\text { LUNG }\end{array}$ & 7 & 5 & 2 & 2 & 5 & 3 & 0.0986 & 0.093 & 0.092 & 0.068 & 1.07 & 1.375 & 6 & 4 \\
\hline
\end{tabular}

Ts (Tv) indicated the number of transition (transversion); $\mathrm{P}_{\mathrm{Ts}}\left(\mathrm{P}_{\mathrm{TV}}\right)$ indicated the sum of the substitution frequency of all the valid transition (transversion). Th 0.01 was to guarantee the observed transitions or transversions were not from system error of sequencing and PCR progress. The value 0 indicated no locati na. indicated no NGS data or calculation unavailable. ${ }^{a}$, questionable results of progeny viruses in MDCK passaging line because of the observed numbers of statistical calculation

Substitution frequency $\left(f_{i}\right)$ for A (Adenine) towards $G$ (Guanine) was higher than that for other types of substitutions on viruses passaged in both MDCK cells and mouse lung. Only for the PB1-reassortant virus, the estimated possibility of transversions $\left(\mathrm{P}_{\mathrm{TV}}\right)$ was higher than that of transitions (Table 3$)$. There was a positive correlation between a higher transition/transversion ratio and a higher non-synonymous mutations ratio for all reassortant viruses. Most of the significant SBS we observed in mouse lung passages were non-synonymous mutations (Fig. 4B). The probability of SBS resulting in a non-synonymous mutation in HA was significantly higher for the PA- and PB1-reassortant viruses after five passages in mouse lung.

\section{Discussions}

Influenza viruses are characterized by rapid mutation caused by error-prone viral RNA-polymerase enzyme on the negative-RNA genome during the replication. In addition, the segmented genome of influenza viruses allows these viruses to obtain novel genetic information by reassortment with other influenza strains. Error-prone RNA polymerase activity may be beneficial for the virus by providing diverse gene mutations that may allow rapid adaptation to a new host. Reassortment may also enable the virus to acquire features from other influenza viruses within short infection circles, thereby possibly rapidly adapted to new host population and becomes endemic or pandemic. Many influenza pandemics in history were caused by reassortant viruses originating from mammalianadapted viruses that obtained genes from avian influenza viruses. For instance, the H1N1 virus causing the 1918 pandemic was a reassortant virus, containing HA from $\mathrm{H} 1$ subtype human-adapted strain and NA and other gene segments from avian influenza viruses [51]. Also the viruses causing the 1957 pandemic [52] and the 2009 pandemic [53, 54] were reassortant viruses.

Considering the pandemic threat of avian influenza viruses, it is important to provide more insight in the characteristics of human influenzas viruses after reassortment with avian influenza viruses. To approach this, we simulated the reassortment of human $\mathrm{H} 1 \mathrm{~N} 1$ virus (inner genes) and avian H9N2 virus (both HA and NA genes, and one of the polymerase genes). The surface genes were derived from the avian H9N2 virus, and the reassortant viruses thus were not adapted to the mammalian receptor. The reassortant viruses in this research were used as a model to study the early stage of evolution of avian-human reassortant influenza viruses. We showed that the RNP complex with the PB1 gene from A2093-H9N2 in the background of the WSN-H1N1 virus significantly promoted the activity of RNPs complex in a Dual-Luciferase Assay System. In MDCK cells, the PB1-reassortant virus was found to replicate with similar efficiency as wt WSN-H1N1 virus. In DF1 cells, the replication of the PB1-reassortant was reduced compared to wt WSN-H1N1 virus. The other reassortant viruses replicated less efficiently in both MDCK and DF1 cells compared to wt WSN-H1N1 virus. The reassortant viruses were able to replicate efficiently in the mouse turbinate and lung, to similar levels as wt WSN-H1N1 virus. Except for the PB2-reassortant virus that showed significantly reduced replication in the mouse lung. The body weight of the mice was measured as an indication for virulence (replication ability) of the viruses. Most interestingly, we observed increased virulence (replication ability) in mice for the PB1-reassortant virus. Due to the low pathogenicity of the virus, no mortality other than decrease in body weight were observed in the infected mice. A previous study detected a high polymerase activity of the combination of mammalian PB2 gene and avian PB1 gene in human cells [55]. The involvement of avian PB1 gene in mammalian-adapted virus might obtain a higher virulence in new host by generating adaptive mutations under a new selection pressure. To obtain more information on the replication and evolution of the WSN-H1N1 virus containing inner gene segments of the avian H9N2 virus, we performed serial passaging of the reassortant viruses in MDCK cells and in mice. 
In this study, the "mutation rate" was calculated during serial passaging of the reassortant viruses. The mutation rate is therefore a combination of initial errors made during RNA replication, combined with the effects of host selection [56]. Mutations in HA may lead to changes of antibody or receptor binding, and may be preferentially selected $[57,58]$. For all reassortant viruses in this study, we observed a higher mutation rate (mutation/site/infection cycle) in mouse lungs compared to MDCK cells. This difference was likely caused by the increased selection pressure mediated by the mouse immune system. The mutation rate measured on HA gene was more than two-fold increased for the PA-reassortant virus compared to wt WSN-H1N1 and A2093-H9N2 viruses, and more than 1.5 times for the PB1-reassortant virus. Previous studies suggested the mutation rate of influenza A viruses ranged from $7.1 \times 10^{-6}$ to $4.5 \times 10^{-5}$ substitutions per nucleotide per cell infection cycle $(\mathrm{s} / \mathrm{n} / \mathrm{c})$ of the whole genome $[59,60]$. In this study, we measured mutation rates of $5.0 \times 10^{-4}$ and $6.2 \times$ $10^{-4}$ mutation/site/infection cycle on HA gene for the PB1 and PA-reassortant virus, which is higher than previously reported. We showed that polymerase activity was increased for the PB1-reassortant virus, which may have resulted in an increased error-rate during RNA replication. However, decreased polymerase activity was measured for the PA-reassortant. The higher mutation rate observed therefore may also result from the strong selection pressure on the reassortant viruses due to their novel genetic composition. We analyzed the HA sequence in this study, and higher selection pressure may be expected for virus surface protein [61]. Furthermore, the mutation rate may not only depend on the gene segment analyzed, but also on the virus subtype as was reported previously [61, 62]. Finally, differences in the analysis methods may have contributed to variation in the error-rates reported [63, 64]. The number/ratio of nonsynonymous mutations is indicator for the selection pressure on the virus [65]. With similar high SBS numbers, the PB1-reassortant virus showed the lowest precentages of non-synonymous changes, whereas in PA-reassortant virus only non-synonymous changes were found. This high percentage of nonsynonymous mutations in PA- reassortant virus was also reflected in a high relative genetic distance, suggesting there is a strong positive selection on the PAreassortant virus. The serial passaging experiments, in which five host-infection circles were observed, showed that the substitution rates of both the PA and PB1-reassortant viruses were increased compared to the other reassortant viruses. This suggests that reassortant virusses obtaining the PB1 gene from avian H9N2 are more likely to rapidly adapt to new hosts. This in accordance with a previous study which showed that virus replication was more efficient when PB1 was derived from an avian virus, regardless of the origin of the other proteins [66]. Furthermore, we identified a mutation hot-spot in the HA-gene, that is located near the antigenic and receptor binding sites [67-69]. We measured a significantly increased substitution frequency for the 350-950 domain of HA1 compared to the complete ORF region. Our results are consistent with previous studies which showed that the head domain of HA evolves faster than the stalk domain [70]. This domain included the 130 helix and 220 loop structure of HA head which are exposed to the surface and therefore can be easily captured by host immune system [71]. Together with the receptor-binding function, the highly mutable HA1 domain might compromise viral replicative fitness, which means the globular head of HA are highly tolerant of mutations [72]. We further indicated that the mutation patterns could be highly influenced by the reassortant viral vRdRp complex, especially in reassortment between human and avian viruses. However, further research will be required to provide more insight in the intracellular mechanism at molecular level.

Reassortment events between human and avian influenza viruses in combination with rapid evolution and adaptation due to error-prone replication may lead to a novel human pandemic. The H9N2 virus is currently the most frequently detected subtype (particularly in live bird markets) and has become endemic in poultry across Asia since 1990s [73]. Several studies provided evidence of interspecies transmission of H9N2 virus from poultry to mammals, such as swine $[74,75]$. Swine may represent "mixing vessel" for influenza viruses as they are susceptible for infected with swine, human and avian influenza viruses [76]. An experimental study showed the replication of H9N2 virus (A/guinea fowl/Hong Kong/WF10/99, A/guinea fowl/Hong Kong/NT184/03) in mice without adaptation [77], likely because of its properties of internal genes related to polymerase function. As human infections with avian H9N2 viruses have been reported $[8,14]$, there is a high probability of reassortment with human influenza viruses.

\section{Conclusions}

In this study, we showed that reassortment between a human H1N1 virus and the avian H9N2 virus might potentially result in a novel virus that can readily adapt to humans: the reassortant virus with the avian PB1 gene showed increased polymerase activity, better replication in mouse lung and high mutation rate at HA gene, in particular in the HA1 domain related to receptor binding and immunogenicity. Therefore, human infections with avian H9N2 viruses and the possible emergence of reassortant influenza viruses carrying avian H9N2 polymerase genes must be carefully monitored for pandemic preparedness.

\section{Abbreviations}

PB2: Polymerase basic protein 2

PB1: Polymerase basic protein 1

PA: Polymerase acidic protein

NP: RNA-binding nucleoprotein

HA: Hemagglutinin Neuraminidase

NA: Neuraminidase

NP: Nucleoprotein

RNP: Ribonucleoprotein

NGS: Next Generation Sequencing

HPAIV: Highly pathogenicity avian influenza virus 
LPAIV: Low pathogenicity avian influenza viruses

AIV: Avian influenza virus

SA: Sialic acid

BSL-2: Biosafety level 2

MDCK: Madin-Darby Canine Kidney

DMEM: Dulbecco's modified Eagle's medium

FBS: fetal bovine serum

SPF: Specific-pathogen-free

ORF: Open reading frame

RLU: Relative light unit

MOI: Multiplicity of infection

SFM: Serum-free cell culture

PFU: Plaque-forming units

PBS: Phosphate-buffered saline

SBS: Single base substitutions

\section{Declarations}

\section{Ethics Statement}

The animal experiment and procedures were in accordance with the recommendations made by the Shanghai Veterinary Research Institute, CAAS (ID: SHVRIP0-2014-0098). The project license was approved by the Animal Association of Science and Technology Commission of Shanghai Municipality, China (Permit Number: 2013-11). All the animal experiments were designed to involved as least number of animals as possible. Animals involved were guaranteed with sufficient food, water and contact space. Animals to be sacrificed for tissues were under euthanasia. All the virus (LPAI H9N2) related materials and experiments were carried out in biosafety level 2 (BSL-2) conditions.

\section{Consent to publication}

Not appliable

\section{Availability of data and material}

All data generated or analysed during this study are included in this published article [and its supplementary information files].

\section{Conflict of interest statement}

There is no conflict of interest for all the authors in this research.

\section{Funding}

This work was supported by the National Key Research and Development Program of China (2016YFD0500204) and the Chinese Academy of Agricultural Sciences of Technology Innovation Project. Nancy Beerens was funded by the Dutch Ministry of Agriculture, Nature and Food Quality (project W0T-01-003-087 and KB-37-003-015).

\section{Authors' contributions}

$\mathrm{HC}$, design of the work, acquisition and analysis, drafted the work; GC, contributed to acquisition and analysis; MdJ, substantial contributions to the conception, interpretation of data; $\mathrm{XL}$, contributed to acquisition; $\mathrm{QL}$, contributed to conception, acquisition and analysis; JY, contributed to acquisition and analysis; QT, contributions to the conception; ZL, contributions to the conception, design of the work, interpretation of data; NB, interpretation of data, substantively revised the paper. All authors read and approved the final manuscript.

\section{Acknowledgements}

We are grateful for the fund and facility supports from Zejun Li's lab group in Shanghai Veterinary Research Institute (SHVIR), China. Hongrui Cui is enrolled through the graduate schools Wageningen Institute of Animal Sciences (WIAS) and Production Ecology and Resource Conservation (PE\&RC) in the 2016 Sino- 
Dutch joint Ph.D. program between the Chinese Academy of Agricultural Sciences (CAAS) and Wageningen University \& Research.

\section{References}

1. Perez DR, Lim W, Seiler JP, Yi G, Peiris M, Shortridge KF, Webster RG: Role of quail in the interspecies transmission of $\mathrm{H} 9$ influenza A viruses: molecular changes on HA that correspond to adaptation from ducks to chickens. Journal of Virology 2003, 77:3148.

2. Lee CW, Song CS, Lee YJ, Mo IP, Garcia M, Suarez DL, Kim SJ: Sequence analysis of the hemagglutinin gene of H9N2 Korean avian influenza viruses and assessment of the pathogenic potential of isolate MS96. Avian Diseases 2000, 44:527-535.

3. Perk S, Panshin A, Shihmanter E, Gissin I, Pokamunski S, Pirak M, Lipkind M, Schudel A, Lombard M: Ecology and molecular epidemiology of H9N2 avian influenza viruses isolated in Israel during 2000-2004 epizootic. Developments in Biologicals 2006, 124:201-209.

4. Lee YJ, Shin JY, Song MS, Lee YM, Choi JG, Lee EK, Jeong OM, Sung HW, Kim JH, Kwon YK: Continuing evolution of H9 influenza viruses in Korean poultry. Virology 2007, 359:313-323.

5. Liu JH, Okazaki K, Mweene A, Shi WM, Wu QM, Su JL, Zhang GZ, Bai GR, Kida H: Genetic conservation of hemagglutinin gene of H9 influenza virus in chicken population in Mainland China. Virus Genes 2004, 29:329-334.

6. Kawaoka Y, Chambers TM, Sladen WL, Webster RG: Is the gene pool of influenza viruses in shorebirds and gulls different from that in wild ducks? Virology 1988, 163:247-250

7. Jackwood MW, Stallknecht DE: Molecular epidemiologic studies on North American $\mathrm{H} 9$ avian influenza virus isolates from waterfowl and shorebirds. Avian Diseases 2007, 51:448-450.

8. Butt K, Smith GJ, Chen H, Zhang L, Leung YC, Xu K, Lim W, Webster RG, Yuen K, Peiris JM: Human infection with an avian H9N2 influenza A virus in Hong Kong in 2003. Journal of clinical microbiology 2005, 43:5760-5767.

9. Peiris M, Yuen K, Leung C, Chan K, Ip P, Lai R, Orr W, Shortridge K: Human infection with influenza H9N2. The Lancet 1999, 354:916-917.

10. Chakraborty A, Arifeen S, Streafield P: Outbreak of mild respiratory disease caused by H5N1 and H9N2 infections among young children in Dhaka, Bangladesh, 2011. Health Sci Bull 2011, 9:5-12.

11. Ali M, Yaqub T, Mukhtar N, Imran M, Ghafoor A, Shahid MF, Naeem M, Iqbal M, Smith GJ, Su YC: Avian influenza A (H9N2) virus in poultry worker, Pakistan, 2015. Emerging Infectious Diseases 2019, 25:136.

12. Alexander DJ: Summary of Avian Influenza Activity in Europe, Asia, Africa, and Australasia, 2002-2006 (Resumen de la actividad de la influenza aviar en Europa, Asia, Africa y Australasia entre los años 2002-2006). Avian Diseases 2007, 51:161-166.

13. Guo Y, Krauss S, Senne D, Mo I, Lo K, Xiong X, Norwood M, Shortridge K, Webster R, Guan Y: Characterization of the pathogenicity of members of the newly established H9N2 influenza virus lineages in Asia. Virology 2000, 267:279-288.

14. Guo Y, Li J, Cheng X: Discovery of men infected by avian influenza A (H9N2) virus. Zhonghua shi yan he lin chuang bing du xue za zhi= Zhonghua shiyan he linchuang bingduxue zazhi= Chinese journal of experimental and clinical virology 1999, 13:105-108.

15. Peacock TTP, James J, Sealy JE, Iqbal M: A global perspective on H9N2 avian influenza virus. Viruses 2019, 11:620.

16. Potdar V, Hinge D, Satav A, Simões EA, Yadav PD, Chadha MS: Laboratory-confirmed avian influenza A (H9N2) virus infection, India, 2019. Emerging infectious diseases 2019, 25:2328.

17. Influenza at the human-animal interface. [https://www.who.int/influenza/human_animal_interface/HAI_Risk_Assessment/en/]

18. Peacock TP, Benton DJ, Sadeyen J-R, Chang P, Sealy JE, Bryant JE, Martin SR, Shelton H, McCauley JW, Barclay WS: Variability in H9N2 haemagglutinin receptor-binding preference and the $\mathrm{pH}$ of fusion. Emerging microbes \& infections 2017, 6:1-7.

19. Huang Y, Li X, Zhang H, Chen B, Jiang Y, Yang L, Zhu W, Hu S, Zhou S, Tang Y: Human infection with an avian influenza A (H9N2) virus in the middle region of China. Journal of Medical Virology 2015, 87:1641-1648.

20. Butt KM, Smith GJD, Chen H, Zhang LJ, Leung YHC, Xu KM, Lim W, Webster RG, Yuen KY, Peiris JSM: Human Infection with an Avian H9N2 Influenza A Virus in Hong Kong in 2003. Journal of Clinical Microbiology 2005, 43:5760-5767.

21. Zhou L, Chen E, Bao C, Xiang N, Wu J, Wu S, Shi J, Wang X, Zheng Y, Zhang Y: Clusters of human infection and human-to-human transmission of avian influenza A (H7N9) virus, 2013-2017. Emerging infectious diseases 2018, 24:397.

22. Guan Y, Shortridge KF, Krauss S, Chin PS, Dyrting KC, Ellis TM, Webster RG, Peiris M: H9N2 Influenza Viruses Possessing H5N1-Like Internal Genomes Continue To Circulate in Poultry in Southeastern China. Journal of Virology 2000, 74:9372.

23. Scholtissek C: Molecular evolution of influenza viruses. Virus Genes 1995, 11:209-215. 
24. Ince WL, Gueyembaye A, Bennink JR, Yewdell JW: Reassortment complements spontaneous mutation in influenza A virus NP and M1 genes to accelerate adaptation to a new host. Journal of Virology 2013, 87:4330-4338.

25. Holmes EC, Ghedin E, Miller N, Taylor J, Bao Y, George KS, Grenfell BT, Salzberg SL, Fraser CM, Lipman DJ: Whole-Genome Analysis of Human Influenza A Virus Reveals Multiple Persistent Lineages and Reassortment among Recent H3N2 Viruses. Plos Biology 2005, 3:e300.

26. Sorrell EM, Wan H, Araya Y, Song H, Perez DR, Palese P: Minimal Molecular Constraints for Respiratory Droplet Transmission of an Avian-Human H9N2 Influenza A Virus. Proceedings of the National Academy of Sciences of the United States of America 2009, 106:7565-7570.

27. Lam TT, Zhou B, Wang J, Chai Y, Shen Y, Chen X, Ma C, Hong W, Chen Y, Zhang Y: Dissemination, divergence and establishment of H7N9 influenza viruses in China. Nature 2015, 522:102.

28. Gu M, Chen H, Li Q, Huang J, Zhao M, Gu X, Jiang K, Wang X, Peng D, Liu X: Enzootic genotype S of H9N2 avian influenza viruses donates internal genes to emerging zoonotic influenza viruses in China. Veterinary microbiology 2014, 174:309-315.

29. Hao X, Wang X, Hu J, Gu M, Wang J, Deng Y, Jiang D, He D, Xu H, Yang Y: The PB2 and M genes of genotype S H9N2 virus contribute to the enhanced fitness of H5Nx and H7N9 avian influenza viruses in chickens. Virology 2019, 535:218-226.

30. Best SM, Kerr PJ: Coevolution of Host and Virus: The Pathogenesis of Virulent and Attenuated Strains of Myxoma Virus in Resistant and Susceptible European Rabbits. Virology 2000, 267:36-48.

31. Li X, Shi J, Guo J, Deng G, Zhang Q, Wang J, He X, Wang K, Chen J, Li Y: Genetics, Receptor Binding Property, and Transmissibility in Mammals of Naturally Isolated H9N2 Avian Influenza Viruses. Plos Pathogens 2014, 10:e1004508.

32. Lindstrom SE, Cox NJ, Klimov A: Genetic analysis of human H2N2 and early H3N2 influenza viruses, 1957-1972: evidence for genetic divergence and multiple reassortment events. Virology 2004, 328:101-119.

33. Fodor E: The RNA polymerase of influenza a virus: mechanisms of viral transcription and replication. Acta virologica $2013, \mathbf{5 7 : 1 1 3 .}$

34. Biswas SK, Boutz PL, Nayak DP: Influenza virus nucleoprotein interacts with influenza virus polymerase proteins. Journal of virology $1998,72: 5493-5501$.

35. Andino R, Rieckhof GE, Achacoso PL, Baltimore D: Poliovirus RNA synthesis utilizes an RNP complex formed around the 5'-end of viral RNA. The EMBO Journal 1993, 12:3587-3598.

36. de la Luna S, Martín J, Portela A, Ortín J: Influenza virus naked RNA can be expressed upon transfection into cells co-expressing the three subunits of the polymerase and the nucleoprotein from simian virus 40 recombinant viruses. Journal of General Virology 1993, 74:535-539.

37. Watanabe T, Watanabe S, Shinya K, Kim JH, Hatta M, Kawaoka Y: Viral RNA polymerase complex promotes optimal growth of 1918 virus in the lower respiratory tract of ferrets. Proceedings of the National Academy of Sciences 2009, 106:588-592.

38. Graef KM, Vreede FT, Lau Y-F, McCall AW, Carr SM, Subbarao K, Fodor E: The PB2 subunit of the influenza virus RNA polymerase affects virulence by interacting with the mitochondrial antiviral signaling protein and inhibiting expression of beta interferon. Journal of virology 2010, 84:8433-8445.

39. Hatta M, Gao P, Halfmann P, Kawaoka Y: Molecular basis for high virulence of Hong Kong H5N1 influenza A viruses. Science 2001, 293:1840-1842.

40. Labadie K, Afonso EDS, Rameix-Welti M-A, Van Der Werf S, Naffakh N: Host-range determinants on the PB2 protein of influenza A viruses control the interaction between the viral polymerase and nucleoprotein in human cells. Virology 2007, 362:271-282.

41. Shinya K, Hamm S, Hatta M, Ito H, Ito T, Kawaoka Y: PB2 amino acid at position 627 affects replicative efficiency, but not cell tropism, of Hong Kong H5N1 influenza A viruses in mice. Virology 2004, 320:258-266.

42. Pappas C, Aguilar PV, Basler CF, Solórzano A, Zeng H, Perrone LA, Palese P, García-Sastre A, Katz JM, Tumpey TM: Single gene reassortants identify a critical role for PB1, HA, and NA in the high virulence of the 1918 pandemic influenza virus. Proceedings of the National Academy of Sciences 2008, 105:30643069.

43. Teng Q, Xu D, Shen W, Liu Q, Rong G, Li X, Yan L, Yang J, Chen H, Yu H, et al: A Single Mutation at Position 190 in Hemagglutinin Enhances Binding Affinity for Human Type Sialic Acid Receptor and Replication of H9N2 Avian Influenza Virus in Mice. Journal of virology 2016, 90:9806-9825.

44. Hoffmann E, Neumann G, Kawaoka Y, Hobom G, Webster RG: A DNA transfection system for generation of influenza A virus from eight plasmids. Proceedings of the National Academy of Sciences of the United States of America 2000, 97:6108-6113.

45. Hatta M, Kawaoka Y: Molecular Basis for High Virulence of Hong Kong H5N1 Influenza A Viruses. Science 2001, 293:1840-1842.

46. Tobita K, Sugiura A, Enomoto C, Furuyama M: Plaque assay and primary isolation of influenza A viruses in an established line of canine kidney cells (MDCK) in the presence of trypsin. Medical microbiology and immunology 1975, 162:9-14.

47. Morelli MJ, Wright CF, Knowles NJ, Juleff N, Paton DJ, King DP, Haydon DT: Evolution of foot-and-mouth disease virus intra-sample sequence diversity during serial transmission in bovine hosts. Veterinary Research 2013, 44:12.

Page $12 / 16$ 
48. Team RC: R: A language and environment for statistical computing. 2013.

49. Van den Hoecke S, Verhelst J, Vuylsteke M, Saelens X: Analysis of the genetic diversity of influenza A viruses using next-generation DNA sequencing. BMC Genomics 2015, 16:79.

50. Yoshikawa T, Matsuo K, Matsuo K, Suzuki Y, Nomoto A, Tamura S-i, Kurata T, Sata T: Total viral genome copies and virus-Ig complexes after infection with influenza virus in the nasal secretions of immunized mice. Journal of general virology 2004, 85:2339-2346.

51. Worobey M, Han G-Z, Rambaut A: Genesis and pathogenesis of the 1918 pandemic H1N1 influenza A virus. Proceedings of the National Academy of Sciences 2014, 111:8107-8112.

52. Kilbourne ED: Influenza pandemics of the 20th century. Emerging infectious diseases 2006, 12:9.

53. Garten RJ, Davis CT, Russell CA, Shu B, Lindstrom S, Balish A, Sessions WM, Xu X, Skepner E, Deyde V: Antigenic and genetic characteristics of swineorigin 2009 A (H1N1) influenza viruses circulating in humans. science 2009, 325:197-201.

54. Smith GJ, Vijaykrishna D, Bahl J, Lycett SJ, Worobey M, Pybus OG, Ma SK, Cheung CL, Raghwani J, Bhatt S: Origins and evolutionary genomics of the 2009 swine-origin H1N1 influenza A epidemic. Nature 2009, 459:1122-1125.

55. Li OT, Chan MC, Leung CS, Chan RW, Guan Y, Nicholls JM, Poon LL: Full factorial analysis of mammalian and avian influenza polymerase subunits suggests a role of an efficient polymerase for virus adaptation. PloS one 2009, 4:e5658.

56. Sanjuán R, Domingo-Calap P: Mechanisms of viral mutation. Cellular and molecular life sciences 2016, 73:4433-4448.

57. Hay AJ, Gregory V, Douglas AR, Lin YP: The evolution of human influenza viruses. Philosophical Transactions of the Royal Society of London Series B: Biological Sciences 2001, 356:1861-1870.

58. Suzuki Y, Gojobori T: A method for detecting positive selection at single amino acid sites. Molecular biology and evolution 1999, 16:1315-1328.

59. Sanjuán R, Nebot MR, Chirico N, Mansky LM, Belshaw R: Viral mutation rates. Journal of virology 2010, 84:9733-9748.

60. Pauly MD, Procario M, Lauring AS: The mutation rates and mutational bias of influenza A virus. bioRxiv 2017:110197.

61. Webster RG, Bean WJ, Gorman OT, Chambers TM, Kawaoka Y: Evolution and ecology of influenza A viruses. Microbiology and molecular biology reviews 1992, 56:152-179.

62. Nobusawa E, Sato K: Comparison of the mutation rates of human influenza A and B viruses. Journal of virology 2006, 80:3675-3678.

63. Pauly MD, Procario MC, Lauring AS: A novel twelve class fluctuation test reveals higher than expected mutation rates for influenza A viruses. Elife 2017, 6:e26437.

64. Parvin JD, Moscona A, Pan W, Leider J, Palese P: Measurement of the mutation rates of animal viruses: influenza A virus and poliovirus type 1. Journal of virology 1986, 59:377-383.

65. Hu T, Banzhaf W: Nonsynonymous to Synonymous Substitution Ratio Ka/ks: Measurement for Rate of Evolution in Evolutionary Computation. In International Conference on Parallel Problem Solving from Nature. Springer; 2008: 448-457.

66. Naffakh N, Massin P, Escriou N, Crescenzo-Chaigne B, van der Werf S: Genetic analysis of the compatibility between polymerase proteins from human and avian strains of influenza A viruses. Microbiology 2000, 81:1283-1291.

67. Ha Y, Stevens DJ, Skehel JJ, Wiley DC: X-ray structures of H5 avian and H9 swine influenza virus hemagglutinins bound to avian and human receptor analogs. Proceedings of the National Academy of Sciences 2001, 98:11181-11186.

68. Wan Z, Ye J, Xu L, Shao H, Jin W, Qian K, Wan H, Qin A: Antigenic mapping of the hemagglutinin of an H9N2 avian influenza virus reveals novel critical amino acid positions in antigenic sites. Journal of virology 2014, 88:3898-3901.

69. Peacock T, Reddy K, James J, Adamiak B, Barclay W, Shelton H, Iqbal M: Antigenic mapping of an H9N2 avian influenza virus reveals two discrete antigenic sites and a novel mechanism of immune escape. Scientific reports 2016, 6:1-12.

70. Kirkpatrick E, Qiu X, Wilson PC, Bahl J, Krammer F: The influenza virus hemagglutinin head evolves faster than the stalk domain. Scientific Reports 2018, 8:10432.

71. Raymond DD, Bajic G, Ferdman J, Suphaphiphat P, Settembre EC, Moody MA, Schmidt AG, Harrison SC: Conserved epitope on influenza-virus hemagglutinin head defined by a vaccine-induced antibody. Proceedings of the National Academy of Sciences 2018, 115:168-173.

72. Doud MB, Bloom JD: Accurate measurement of the effects of all amino-acid mutations on influenza hemagglutinin. Viruses 2016, 8:155.

73. Alexander DJ: An overview of the epidemiology of avian influenza. Vaccine 2007, 25:5637-5644.

Page $13 / 16$ 
74. Cong Y-L, Wang C-F, Yan C-M, Peng J-S, Jiang Z-L, Liu J-H: Swine infection with H9N2 influenza viruses in China in 2004. Virus genes 2008, 36:461-469.

75. Yu H, Hua R-H, Wei T-C, Zhou Y-J, Tian Z-J, Li G-X, Liu T-Q, Tong G-Z: Isolation and genetic characterization of avian origin H9N2 influenza viruses from pigs in China. Veterinary microbiology 2008, 131:82-92.

76. Ma W, Kahn RE, Richt JA: The pig as a mixing vessel for influenza viruses: human and veterinary implications. Journal of molecular and genetic medicine: an international journal of biomedical research 2009, 3:158.

77. Choi YK, Ozaki H, Webby RJ, Webster RG, Peiris JS, Poon L, Butt C, Leung YHC, Guan Y: Continuing Evolution of H9N2 Influenza Viruses in Southeastern China. Journal of Virology 2004, 78:8609-8614

\section{Figures}

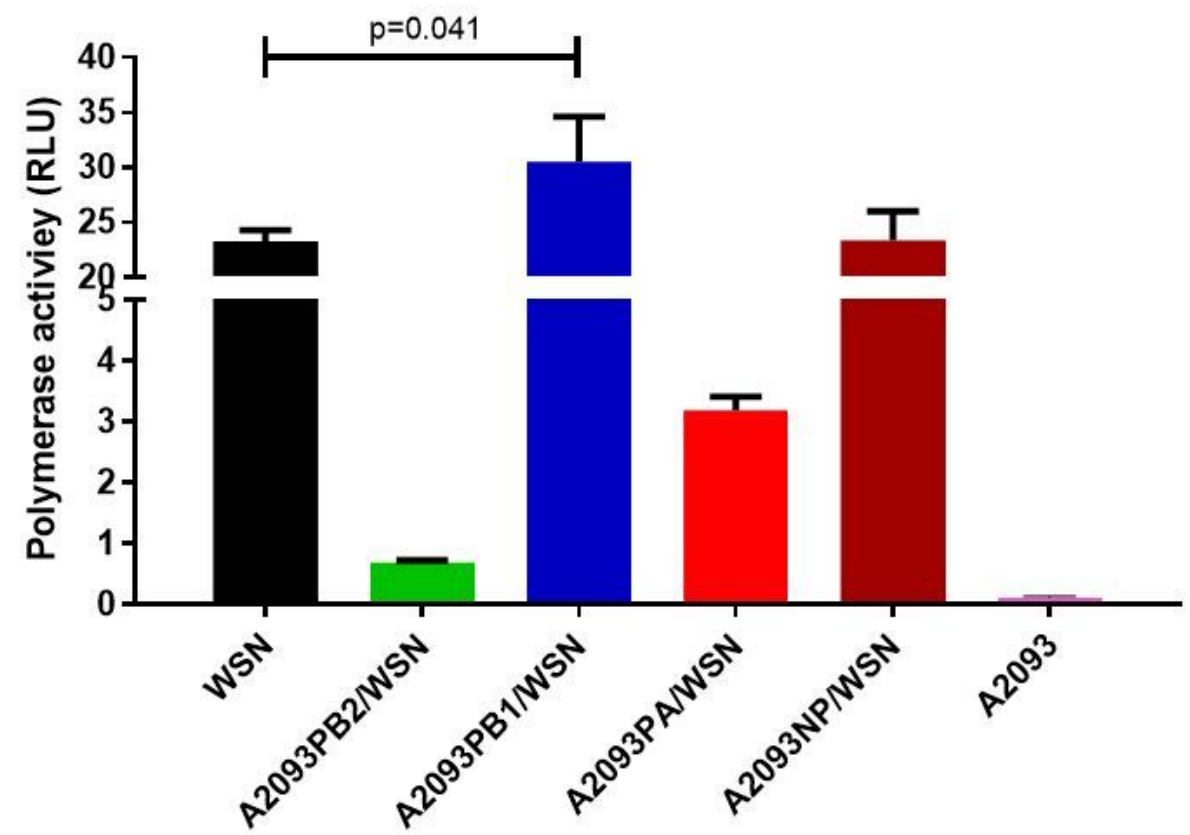

Figure 1

Viral RNPs functional assay of recombinant polymerase complex. The polymerase activities of the human WSN-H1N1 RNP, the recombinant RNPs containing PB2, PB1, PA or NP genes derived from the avian A2093-H9N2 RNP, and the avian H2093 RNP were measured using the Dual-Luciferase Assay System. Firefly luciferase activity was measured to determine polymerase activity, and Renilla luciferase activity was used as an internal control for monitoring transfection efficiency. Experiments were repeated three times, mean and SD were applied. Multiple t-test with $a=0.05$. *significant difference. 
A
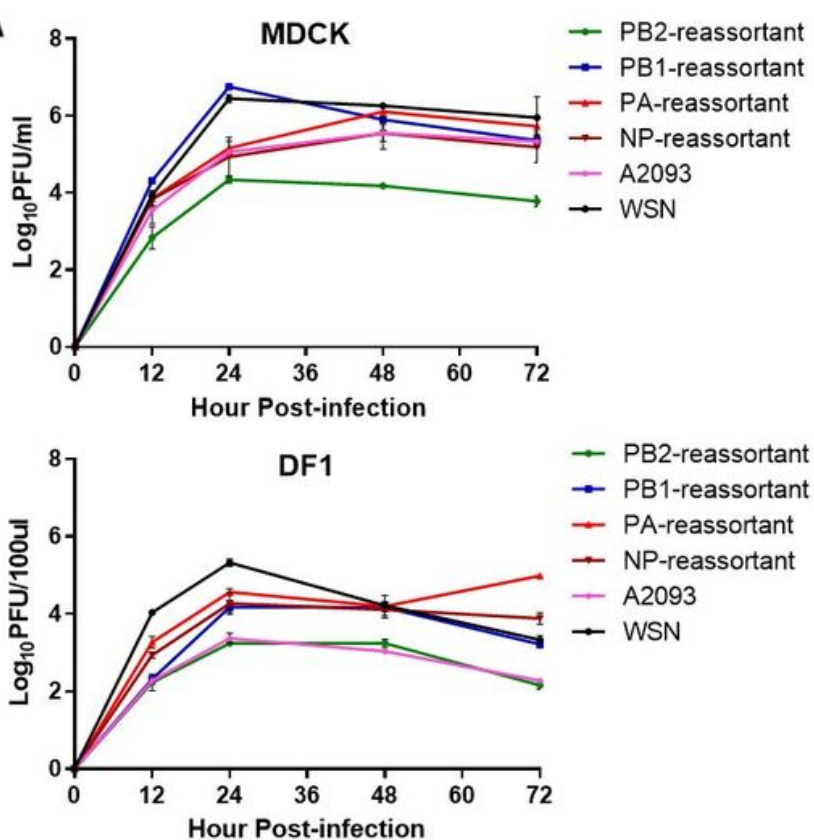

B

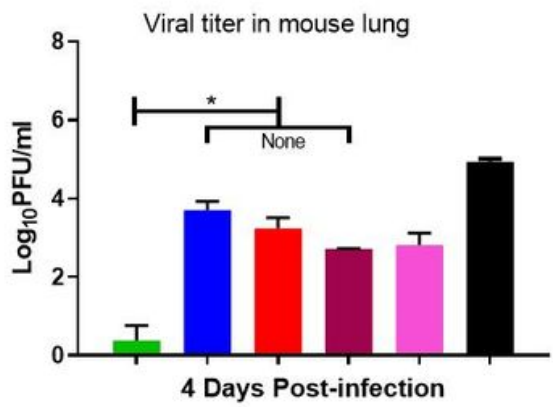

PB2-reassortant

- PB1-reassortant

- PA-reassortant

- NP-reassortant

- A2093

WSN

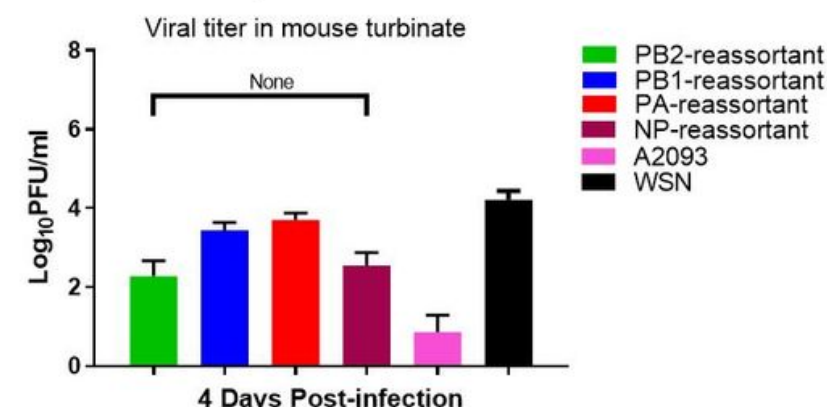

Figure 2

Replication of reassortant viruses in cell lines (A) and in mouse (B). A, Virus replication of human wt WSN1-H1N1, avian wt 2093-H9N2 and reassortant viruses containing the avian PB2, PB1, PA or NP segments. Virus replication was measured by determining plaque forming units at several hours post infection of MDCK and DF1 cells. B, Virus replication of human wt WSN1-H1N1, avian wt 2093-H9N2 and reassortant viruses containing the avian PB2, PB1, PA or NP segments. Virus replication in mouse turbinal tissue and lung was measured at. 4 days post infection using plaque assays. Plaque assays were repeated three times, the mean and sd of the PFU in logarithm of 10 was applied. Multiple t-test with a $=0.05$. * significant difference.

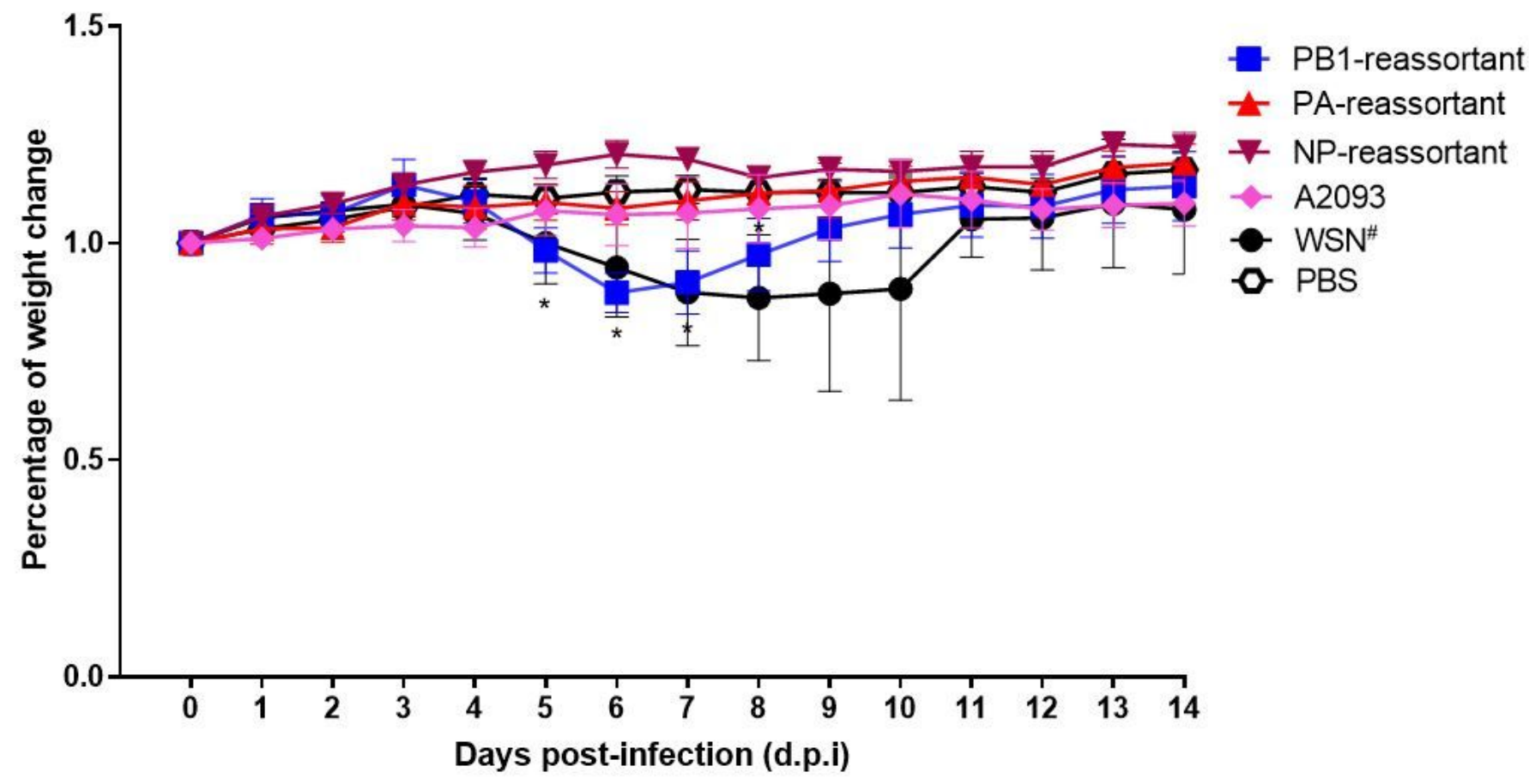

Figure 3

Virulence of reassortant viruses in mice. Virulence of the PB1-, PA- and NP-reassortant viruses was measured by infection of five mice, after which body-weight loss was measured for 14 days after infection. For reference, the human wt WSN-H1N1 and avian wt A2093-H9N2 viruses are shown. The percentage of body weight loss is plotted, and significant differences (Multiple t-test with $a=0.05)$ are marked $(*)$. The percentage weight changes in body weight $(n=5)$ are expressed as the mean with SD in each group. \# One mouse died on day 8,9 and 11 d.p.i. 
A

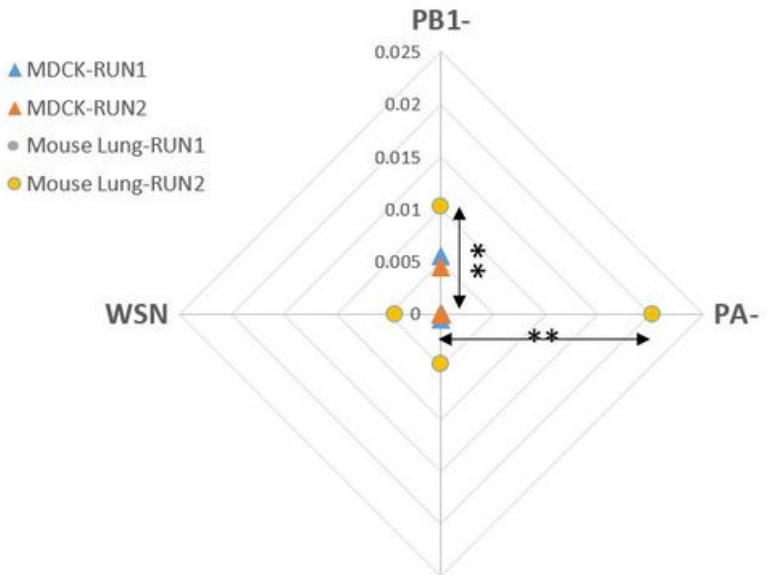

NP-
B

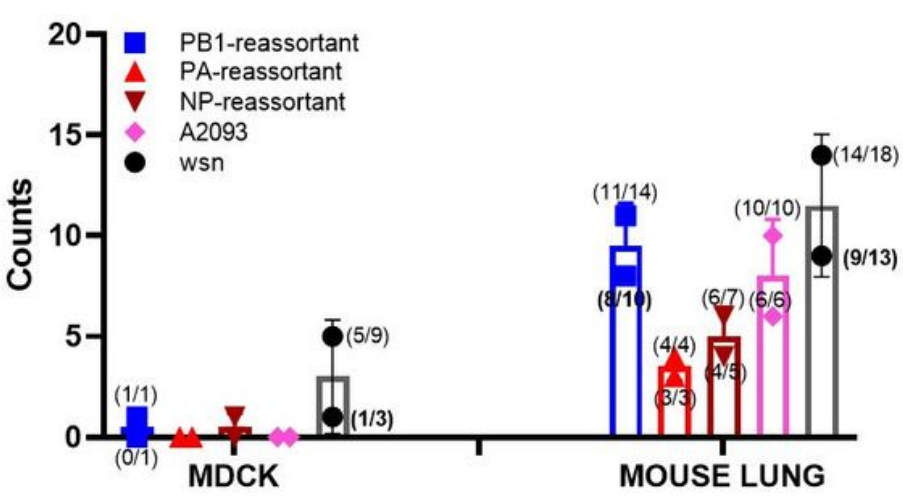

Figure 4

Genetic variation in the HA sequence after passaging of reassortant viruses. A. Genetic distance of HA sequences. The genetic distance of the HA sequences of the PB1-, PA- and NP-reassortant viruses after five passages in MDCK cells (triangles) and mouse lung (circles) is plotted relative to the wt A2093-H9N2 virus. The genetic distance of the WSN-H1N1 after five passages is plotted relative to the wt WSN-H1N1 virus. Two independent experiments were performed in cells and mice, that were analyzed by NGS and are plotted separately, as RUN1 and RUN2. Further details on the NGS results are shown in Supplementary Table S5. ** significant difference in the genetic distance compared to the WSN-H1N1 strain. B, Non-synonymous numbers over open read frame (ORF) of HA nucleotide sequence. The number of substitutions (SBS) is plotted for the PB1, PA and NP reassortant viruses, and the wt A2093-H9N2 and WSN-H1N1 viruses, after passaging in MDCK cells and mice lung. Numbers in the bracket indicated non-synonymous numbers with $\mathrm{Fi}>0.01$, and the total SBS number separating by "/".

\section{Supplementary Files}

This is a list of supplementary files associated with this preprint. Click to download.

- Additionalfile1.pptx

- Additionalfile2.xlsx 